Article

\title{
On the Relationship between Creep Strain and Permeability of Granite: Experiment and Model Investigation
}

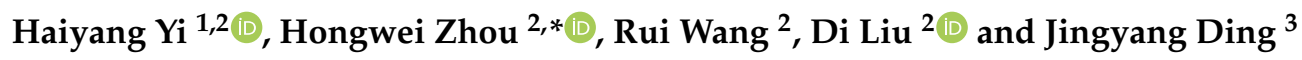 \\ 1 School of Civil Engineering, Southwest Jiaotong University, Chengdu 610031, China; \\ yihaiyangchina@gmail.com \\ 2 School of Mechanics and Civil Engineering, China University of Mining and Technology, Beijing 100083, \\ China; mcoffee@163.com (R.W.); diligentkids@sohu.com (D.L.) \\ 3 Beijing Institute of Geological \& Prospecting Engineering, Beijing 100048, China; ak47djy@sina.com \\ * Correspondence: zhw@cumtb.edu.cn; Tel.: +86-10-6233-1286
}

Received: 7 October 2018; Accepted: 18 October 2018; Published: 22 October 2018

\begin{abstract}
Granite is regarded as a good option of host rock for high-level radioactive waste (HLW) repositories. Despite of its creep strain is small, the creep damage of which, especially that in the accelerated creep stage, increase its permeability significantly. To investigate the relationship between the creep strain and permeability evolution in granite, the present paper conducted a set of creep-seepage experiments associated with acoustic emission (AE) technology. The analysis in terms of the evolution of creep strain and permeability, characters of AE hits, mechanism of creep strain and that of permeability convince us that, the permeability evolution of granite is related to the volumetric dilation and microcracks connectivity. According to this relationship, a three-dimensional damage-based creep model was deduced from a one-dimensional fractal derivative-based model, and a permeability evolution model was proposed as well in this paper. The experiment data suggest nonnegligible influence of creep damage on the permeability of granite, therefore this influence should be taken into consideration of the design work of HLW repositories. The calculated results of the proposed models match well the experiment data, suggesting good capability of the models in approaching the creep and hydraulic performance of granite. In addition, the permeability model is friendly in parameter identification due to its simple mathematic formulation.
\end{abstract}

Keywords: granite; creep damage; repository; acoustic emission; fractal derivative; permeability; three dimensional creep model

\section{Introduction}

Nuclear waste disposal is a serious issue for nuclear energy. It has been considered by most countries that, deep geological disposal is an efficient approach for nuclear waste disposal [1]. Therefore, high-level radioactive waste (HLW) repositories have been planned in many countries, targeting at isolating the long-lived radionuclide from biosphere in a very long term [2]. Granite has been recognized as a good option of host rock for HLW repositories, due to its high performance of strength and low permeability. While during such a long duration of nuclide decay, although the creep strain of granite is small due to its brittle performance, evidence from previous creep experiments of brittle rocks suggest that, the creep damage change the permeability of brittle rocks obviously [2-6]. Therefore, a good understanding of the relationship between creep strain and permeability evolution of granite, in terms of the evolution characters of creep strain, permeability and creep damage, mechanism of permeability evolution and models of the creep strain and permeability, is essential to the safety assessment of repositories. 
As mentioned by Chen [2,7], less literatures reported the creep behavior of granite due to the negligible creep deformation, whereas increasingly interest was devoted on this aspect in the last decades with the recognition of granite as the host rock of HLW repository [8-11]. A review on the principal experiments of the creep behaviors of granite by Hashiba [12] suggests that, previous studies on the creep behavior of granite mainly focused on the creep mechanism, long-term strength, evolution of creep strain and microcracks, damage characters, effect of confining pressure and temperature, etc. While previous studies on the influence of creep process on the permeability evolution are rare [3].

In fact, like most of other rock materials, creep damage has been proofed by experiments as a main reason of creep strain and failure in granite, exhibiting microcracks initiate and propagate to a critical state [7]. Precisely because of the microcracks initiation and propagation, which provide potential channels for fluid. Liu [3] indicated that both the creep strain and permeability of granite keep steady in the steady creep stage but increases rapidly in the accelerated creep stage. By application of acoustic emission (AE) technology, Chen [7] observed the AE hits and creep strain of granite increase slowly in the steady creep stage but dramatically in the accelerated creep stage. Despite of above achievement in the mechanism of creep damage and permeability evolution in the creep process of granite. The relationship between creep deformation and permeability evolution is still not clear, especially theoretical models for describing this relationship.

The model for representing the creep deformation of rock materials are various, basically, these models can be categorized into empirical models, component models and mechanism-based constitutive models [7]. In recent years, creep models based on damage evolution for granite is increasingly accepted by scholars, their damage-based models were verified well by experiments [7,12-15]. By employing fractional derivatives to describe the variable velocity of materials due to creep damage, fractional derivatives-based creep models are raising the interest of researchers in recent years. These fractional derivatives-based creep models are clarified to be more accurate in reproducing the creep phenomena of materials with fewer parameters due to explicit mathematical expression [16-20]. It is notable that, most of above creep models are one-dimensional, however, Liu [21] pointed out that the permeability evolution of granite is related to the volumetric strain in the creep process. Therefore, in order to build a bridge between the creep strain and permeability, further studies of the fractional derivatives-based model considering damage evolution should be conducted targeting its three-dimensional form.

Few studies involved on the model of permeability evolution in creep process of granite due to complex process of structural evolution. Cao [5] and Liu [21] proposed empirical models based on volumetric strain, their model results fitted well the experiment data. Denoted by Jang [22] and Zhao [23], permeability change during compression of brittle rocks is attributed to the density and opening of microcracks. Chen [24] observed random microcracks emerge in the primary creep phase, these microcracks propagate and interact mutually in the secondary creep phase, and in the tertiary creep phase, cracks interact massively and form large cracks eventually. Chen [25] explained the changes of permeability and volumetric strain in granite are attributed to the initiation, propagation and coalescence of microcracks, exhibiting slightly decreased in the primary creep phase, kept stable in the secondary creep phase and increased rapidly in the tertiary creep phase. All of above studies convince us that, both the creep strain and permeability are controlled by the evolution of microcracks. In other words, it is feasible to build models of creep strain and permeability evolution with a consideration of creep damage in the view of microcracks evolution.

Motivated by above status, the present paper implemented a creep-seepage experiment with associate of $\mathrm{AE}$ technology, aiming at analysis of the evolution characters of creep strain, permeability and creep damage. Based on the analysis, A three-dimensional fractal derivatives creep model was deduced thereafter. According the influence of creep damage on the permeability evolution, the present paper built the relationship between creep strain and permeability evolution by a permeability model. Finally, both the damage-based creep model and permeability model were verified by the experiment data of this paper and referenced experiment data. 


\section{Experiment on Creep-Seepage of Granite}

\subsection{Specimen Preparation and Experiment Equipment}

Experiment specimens were manufactured from the borehole of BS06 at a depth ranged from $450 \mathrm{~m}$ to $550 \mathrm{~m}$ in Xinchang subarea Beishan Gansu province, where is a potential site for the HLW repository of China. According to the Standard for Test Method of Engineering Rock Mass (GB/T50266-99, China), testing specimens were polished with dimensions of $50 \mathrm{~mm}$ in diameter and $100 \mathrm{~mm}$ in height.

A rock mechanics testing system MTS815 and a three-dimensional AE system were employed in the experiment of this paper. The MTS815 used in the experiment has capacities of maximum axial load, confining pressure and hydraulic pressure up to $4600 \mathrm{kN}, 140 \mathrm{MPa}$ and $140 \mathrm{MPa}$, respectively. An axial extensometer and two linear variable differential transformers (LVDT) were used to record the axial deformation, and a circumferential extensometer was applied for measuring the circumferential strain. The microcracking process during the experiment was detected by the AE system.

\subsection{Experiment Method and Procedure}

To investigate the influence of different creep damage status on the permeability of granite, a set of multi-step creep-seepage experiments were implemented in this paper. The tested granite came from the surrounding rock after excavation.

As denoted by Chen $[2,25]$, the average earth pressure in Beishan region ranged from $400 \mathrm{~m}$ to $600 \mathrm{~m}$ in depth is approximately $15 \mathrm{MPa}$, while the excavation of chamber will reduce the earth pressure remarkably due to stress redistribution in the excavation disturbance zone (EDZ). Thus, three specimens were tested at confined pressures of $3 \mathrm{MPa}, 6 \mathrm{MPa}$ and $9 \mathrm{MPa}$, respectively. Correspondingly, the tested specimens were named by CS_3, CS_6 and CS_9, in which CS represents creep-seepage tests and the number after $C S$ means applied confining pressure. Conventional uniaxial compression tests were implemented prior to the creep experiment, suggesting the average compressive strength of the tested granite is about $110 \mathrm{MPa}$. As demonstrated by Chen [25], when a load overpasses the critical damage stress of granite that the microcracks propagate and volumetric dilation appear, therefore, in order to identify the influence of volumetric dilation on the permeability of granite, the initial axial force was designed slightly lower than the critical damage stress empirically, thereby avoiding volumetric dilation intially and obtaining volumetric dilation later with higher axial pressures. In the multi-step creep tests of this paper, an initial axial load of $90 \mathrm{MPa}$, approximately $75 \%$ of the compressive strength was loaded in the first step, then the axial load was improved by $15 \mathrm{MPa}$ for each step until the tested specimen was broken, the duration of each creep step was designed by $10 \mathrm{~h}$. The permeability of tested specimen was measured by the transient method, which is a common and effective method for permeability measurement on low permeable medium [26,27]. The hydraulic pressure in the experiments was set as $1 \mathrm{MPa}$. Eight AE sensors were placed on the surface of the tested specimen to detect the damage distribution in its creep process, the sampling rate of the applied $\mathrm{AE}$ system is $100 \mathrm{Msps}$, a frequency of which ranged from $150 \mathrm{kHz}$ to $1000 \mathrm{kHz}$ and a threshold of $28 \mathrm{~dB}$ were applied during the experiments. The loading platform and specimens are depicted in Figure 1.

Prior to the creep experiment, the tested specimens were saturated by distilled water under vacuumed environment over $12 \mathrm{~h}$, and then the specimens were wrapped by thermal plastic membranes. After a specimen was installed in the loading platform, the confining pressure was loaded by a rate of $3 \mathrm{MPa} / \mathrm{min}$ to the target value. Thereafter, the hydraulic pressure was increased gradually until the difference of hydraulic pressure at two ends of the specimen reached to $1 \mathrm{MPa}$. Finally, the axial pressure was applied by $30 \mathrm{kN} / \mathrm{min}$ to the designed value of each creep step. During each creep step, the hydraulic pressure differential at two ends of the tested specimen were automatically measured to calculate the permeability, following the form [7]. 


$$
k=\mu \beta V \frac{\ln \left(\Delta P_{i} / \Delta P_{f}\right)}{2 \Delta t A_{s} / L_{s}}
$$

where $\Delta P_{i} / \Delta P_{f}$ means the ratio of initial pressure differential to final pressure differential over the measuring time of $\Delta t(s)$. Since the fluid used in the experiment is water, the viscosity of $0.001 \mathrm{~Pa} \cdot \mathrm{s}$ and a compressibility of $4.53 \times 10^{-10} \mathrm{~Pa}^{-1}$ were applied for calculations.
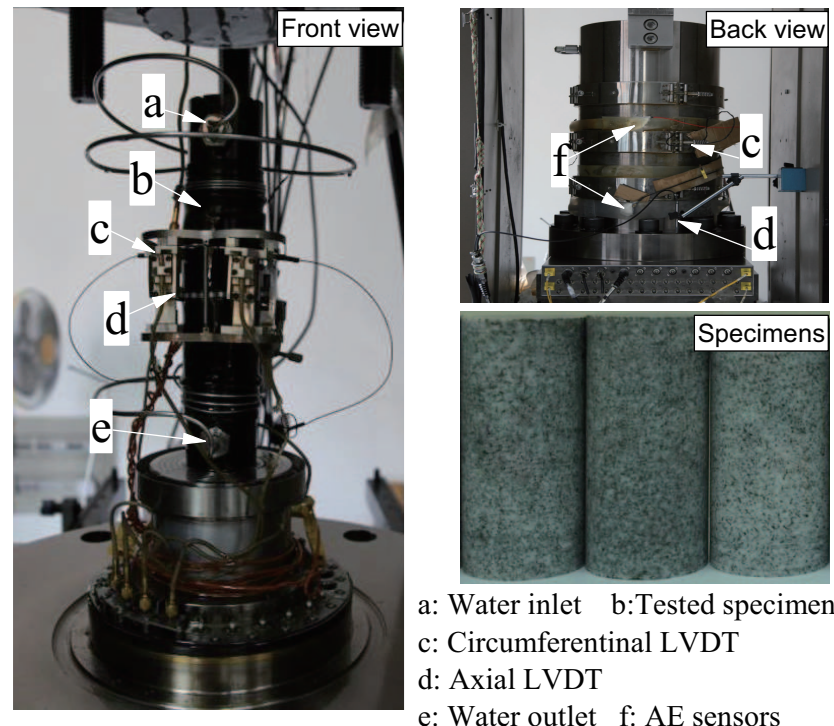

a: Water inlet b:Tested specimen

c: Circumferentinal LVDT

d: Axial LVDT

e: Water outlet f: AE sensors

Figure 1. Loading platform and specimens of the experiment.

Once the hydraulic pressure was measured, the difference of hydraulic pressure at two ends of the specimen was recovered to $1 \mathrm{MPa}$. For time saving, the amplitude of axial pressure for the specimen with a confining pressure of $9 \mathrm{MPa}$ was modified by $30 \mathrm{MPa}$ in previous steps. The AE hits, axial and circumferential strain of the whole steps for every creep experiment were recorded automatically by a computer, the volumetric strain was calculated following $\varepsilon_{v}=\varepsilon_{a}+2 \varepsilon_{c}$, in which $\varepsilon_{m}, \varepsilon_{a}$ and $\varepsilon_{c}$ denote volumetric, axial and circumferential strain, respectively. In the experiment, the positive value of strain means the tested specimen was compressed, on the contrary, the negative one denotes tensile state of the involved specimen.

\section{Experiment Results and Analysis}

\subsection{Evolution of Creep Strain and Permeability}

The results of creep-seepage experiment are depicted in Figure 2. As a whole, the specimen CS_3 failed at the third creep step, the one CS_6 experienced 4 creep steps and soon failed at the beginning of the fifth step, while the one CS_9 failed in the sixth creep step. In the first creep step of all the tested specimens, the measured axial and volumetric strain increased promptly but slowly thereafter, initially, the circumferential strain decreased soon but slightly until the next creep step, exhibiting typical transient state and steady state. However, when the specimen CS_3 got into the second creep step, see Figure 2a, the axial strain and circumferential strain showed the same tendency as that of the first step, except the volumetric strain which increased immediately but reduced gradually. This phenomenon was also observed in the third and the forth creep steps of CS_6 (Figure 2b), and the forth to the sixth creep steps of CS_9 (see Figure 2c). In the last creep steps of CS_3 and CS_9, the specimen experienced both the transient and steady creep phases but also the accelerated phase, showing the rapid increase of axial strain and dramatic drop of circumferential strain and volumetric strain. Unfortunately, CS_6 failed in the loading process of the last creep step. 


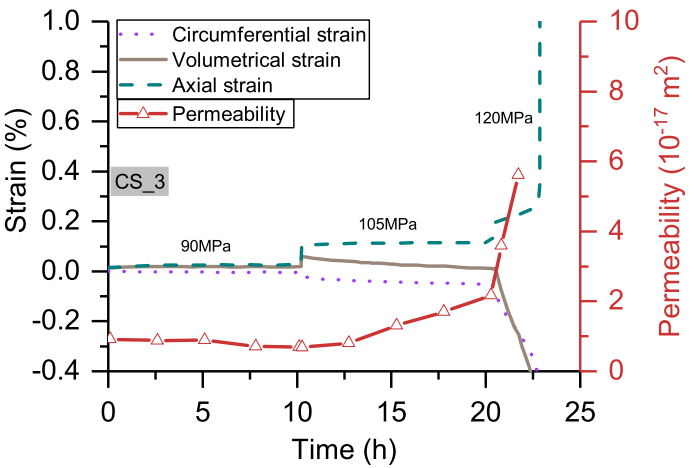

(a)

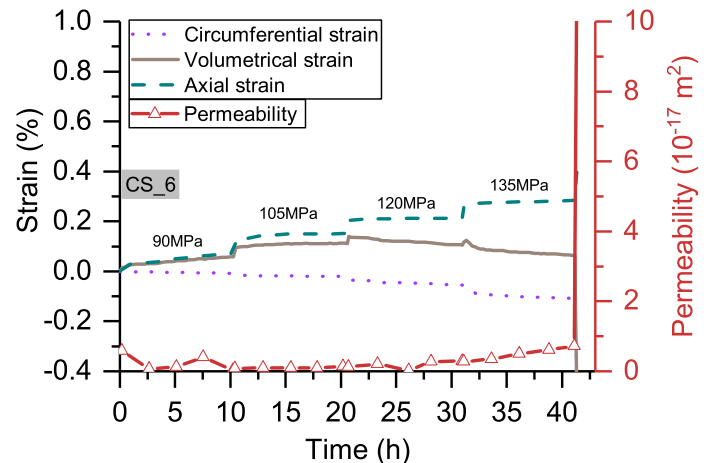

(b)

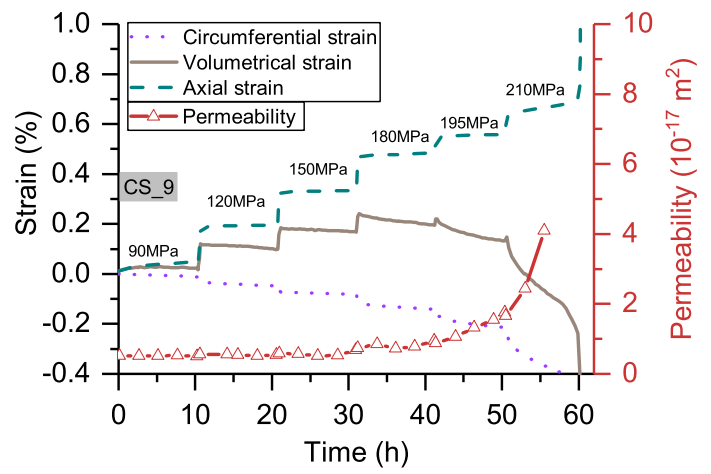

(c)

Figure 2. Experiment data of creep strain and permeability in specimens (a) CS_3 (b) CS_6 and (c) CS_9.

Interestingly, the volumetric strain of all the three specimens experienced increase (volumetric compression) in the first or former creep steps, but decreased (volumetric dilation) after the axial pressures were higher than certain values. Correspondingly, the measured permeability almost remained stable in volumetric compression, see Figure 2, once volumetric dilation occurred, the permeability went up obviously, especially in the last creep step, the permeability increased dramatically. The measured results in permeability of Liu [3] by steady-state method show the similar tendency to our cases, permeability increased slightly and then promptly following the volumetric dilation of tested specimens.

All above analysis illustrates that the permeability evolution of granite is mainly related to the volumetric dilation of granite in creep process, especially in the accelerated creep state, the permeability of specimens was enlarged dramatically, the influence of volumetric compression on its permeability is very limited. Therefore, the permeability change of granite in creep process is nonnegligible and a three-dimensional creep model is a necessity for describing the relationship between creep strain and permeability evolution of granite.

\subsection{Characters of Acoustic Emission Hits}

Creep damage has been regarded as a controlling factor of creep deformation and permeability, whereas it is important to understand the mechanism of permeability evolution in the full processes of creep damage, outstanding the microcracks initiation, microcracks propagation and microcracks interaction, which one mainly contributes to the permeability evolution, thereby building models for the creep strain and permeability evolution. The characters of AE hits detected in the creep-seepage experiments were analyzed in this subsection.

As in Figure 3a, there was a small number of AE hits appearing in the first creep step of CS_3. However, increased AE hits occurred in the upper and lower areas in the second creep step, in this creep 
step, volumetric dilation appeared and the permeability of CS_3 went up gradually. Once the creep step got into the third one, AE hits occurred in the whole specimen which lead to remarkable changes of volumetric dilation and permeability. The spatial distribution of AE hits in CS_6 is illustrated in Figure 3b, obviously, AE hits occurred in the upper area of the specimen in both the first and second creep steps, while few of which in the lower area, correspondingly, no volumetric dilation occurred and the permeability kept stable. Once CS_6 submerged to higher axial pressures in the third and the forth creep steps, AE hits in the lower area increased and resulted in volumetric dilation, whereas the change of permeability was slight. In CS_9, see Figure 3c, few AE hits were raised in the first and second creep steps, similar to CS_6, the changes of volumetric strain and permeability of CS_9 were very limited. When higher axial pressures were applied to the specimen in the third and the forth creep steps, both volumetric strain and permeability of CS_9 were promoted slightly with increasing $\mathrm{AE}$ hits distributed in the upper and lower areas of the specimen. In the fifth and the sixth creep steps, a large amount of $\mathrm{AE}$ hits were produced in the specimen, which improved the volumetric dilation and permeability of CS_9 quickly.

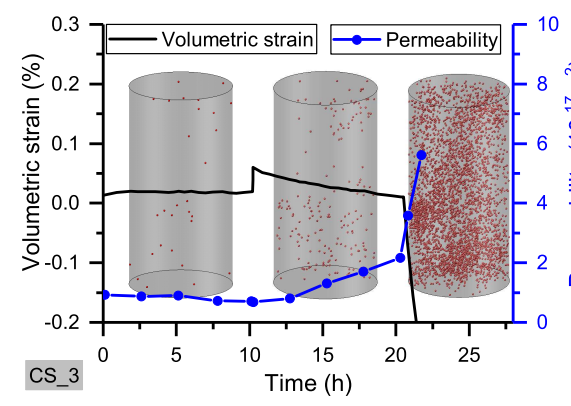

(a)

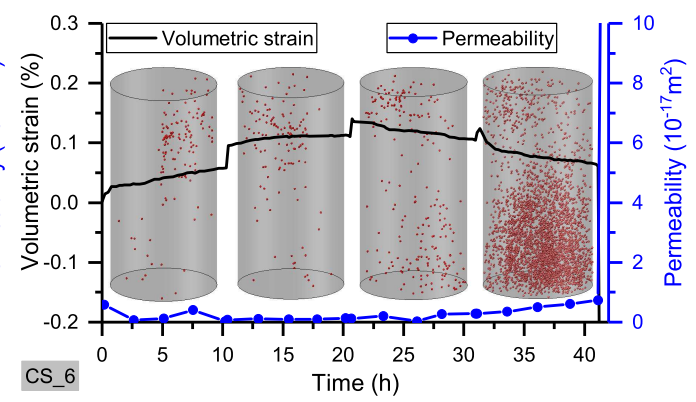

(b)

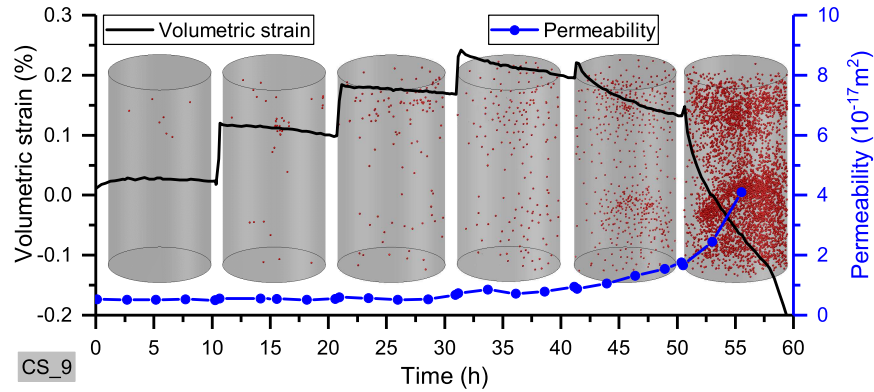

(c)

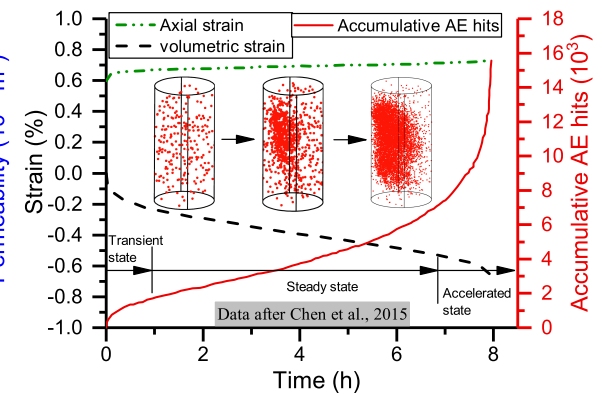

(d)

Figure 3. Spatial distribution of AE hits at each creep step of specimens (a) CS_3 (b) CS_6 (c) CS_9 and (d) data of creep after Chen [25].

Obviously, the spatial distributions of AE hits in the creep steps of all the three specimens convince us that, both the volumetric strain and permeability are influenced by the creep damage. While the evolution degree of permeability depends on the area of AE distribution, saying both the upper and lower areas were damaged, thereby promoting the permeability of the tested specimens. Generally, every AE hit can be regarded as a microcrack initiated in the tested specimen, thus when microcracks appeared in the whole internal structure of the specimen and formed potential fluid channels, then the permeability was increased.

For the volumetric strain of granite, as it is shown in Figure 3d, Chen [25] pointed out that once the loading pressure is over the critical value of damage, microcracks will occur, propagate and form into meso cracks, resulting in transient, steady and accelerated states in one-step creep processes. The measured data in axial strain, volumetric strain and accumulative AE hits of Chen [25] show the similar tendency as the last creep step of our cases (see Figures $3 \mathrm{~d}$ and 4). Logically, the measured volumetric strain contains the strain of solid bulks and voids of microcracks. Under compressive load, 
the strain of solid bulks would increase due to shrinkage of porous structure, resulting in volumetric compression. While the increase of microcracks would expand the voids of microcracks, thereby decreasing the volumetric strain and exhibiting volumetric dilation.

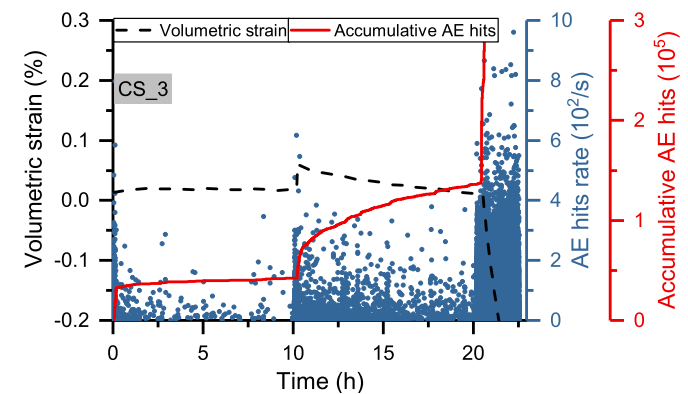

(a)

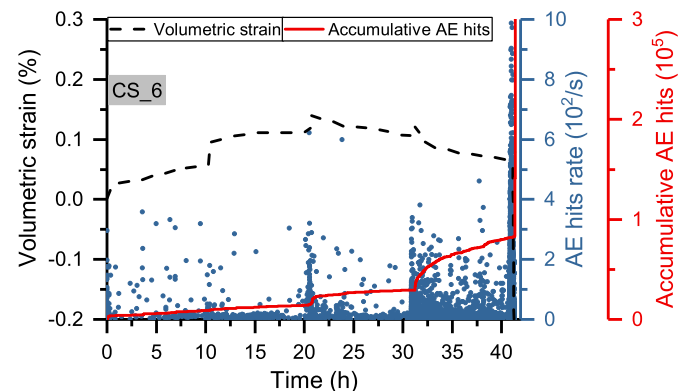

(b)

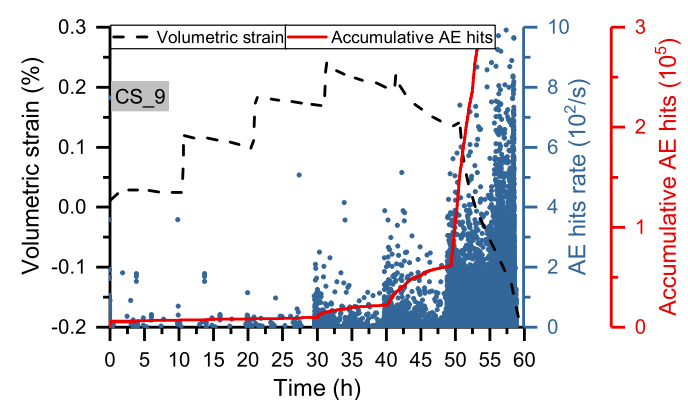

(c)

Figure 4. AE hits and volumetric strain versus creep time of (a) CS_3 (b) CS_6 and (c) CS_9.

As in Figure 4, transient increase of $\mathrm{AE}$ hits rates and accumulative $\mathrm{AE}$ hits occurred at the initial stage of every creep step, while in the first or second creep steps of the involved specimens, the volumetric strain was increased gradually by the decreasing AE hits rates. Obviously, the volumetric strain of the specimens was controlled by the strain of solid bulks, saying volumetric compression. Once a large amount of transient microcracks occurred, see the second or third creep steps in Figure 4, both the AE hits rates and accumulative AE hits were increased, whereas the volumetric strain was decreased. It means the voids of microcracks prevailed, exhibiting volumetric dilation. Therefore, the volumetric strain of granite in creep process is controlled not only by the strain of solid bulks, but also by the voids of microcracks.

\section{Model Investigation on Creep Strain and Permeability}

\subsection{A Three-Dimensional Creep Strain Model}

According to the analysis in above section, the evolution of permeability is related to the volumetric strain of granite, a three-dimensional creep model is required for describing the mechanical and hydraulic performance of granite in creep-seepage processes. In addition, the creep strain of granite is controlled by the damage states. For this purpose, a damage-based creep model is deduced in this subsection.

Among classic creep models, Nishihara model is accepted as a common and useful model for its ability of describing the elastic-viscoelastic and viscoplastic behaviors of materials. Outstanding the damage mechanism of creep process, Zhou $[16,17]$ developed the Nishihara model based on a damage model and fractional derivative theory, targeting at reproducing the full creep regions of salt rock in one mathematic formulation. According to this concept, Wang [19] modified the damage-mechanism-based creep model of Zhou $[16,17]$ by fractal derivative, the concept model is shown in Figure 5. 


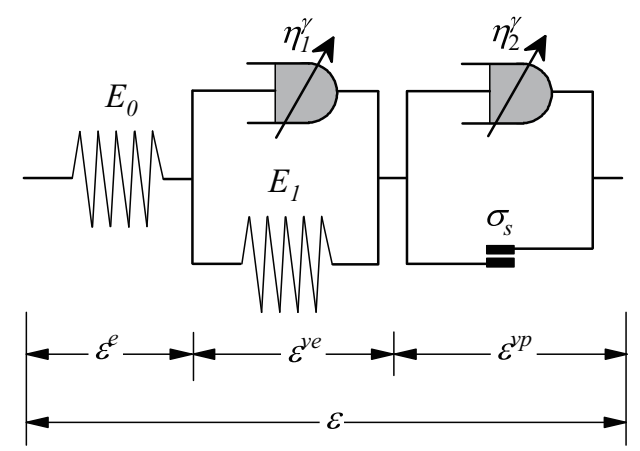

Figure 5. Schematic view of damage-mechanism-based fractal derivative creep model.

According to the concept of Nishihara model, the total creep strain can be expressed as

$$
\varepsilon=\varepsilon^{e}+\varepsilon^{v e}+\varepsilon^{v p}
$$

In the model of Wang [19], the elastic, viscoelastic and viscoplastic strain is in the forms of

$$
\begin{gathered}
\varepsilon^{e}=\frac{\sigma}{E_{0}}, \\
\varepsilon^{v e}=\frac{\sigma}{E_{1}}\left[1-\exp \left(-E_{1} t^{\gamma_{1}} / \eta_{1}\right)\right], \quad\left(\sigma<\sigma_{s}\right) \\
\varepsilon^{v p}=\frac{\sigma-\sigma_{s}}{\eta_{2} \alpha}\left[\exp \left(\alpha t^{\gamma_{2}}-1\right)\right], \quad\left(\sigma \geq \sigma_{s}\right)
\end{gathered}
$$

In the three-dimensional space, based on Equation (3), the total strain of a representative volume element yields

$$
\varepsilon_{i j}=\varepsilon_{i j}^{e}+\varepsilon_{i j}^{v e}+\varepsilon_{i j}^{v p} .
$$

According to Terzaki principle, the effective stress attributing to the strain of materials following the form of

$$
\sigma_{i j}^{\prime}=\sigma_{i j}-P \delta_{i j}
$$

In Hook's law, the three-dimensional elastic strain is expressed as

$$
\varepsilon_{i j}^{e}=\frac{1}{2 G_{0}} s_{i j}+\frac{1}{3 K_{0}} \sigma_{m} \delta_{i j} .
$$

As mentioned by Qi [28], creep of rock materials in viscoelastic region can be regarded as shearing deformation. Corresponding to Equation (4), the three-dimensional viscoelastic strain following

$$
\varepsilon_{i j}^{v e}=\frac{s_{i j}}{2 G_{1}}\left[1-\exp \left(-G_{1} t^{\gamma_{1}} / \eta_{1}\right)\right]
$$

In the light of Perzyna viscoplastic flow rule [29], the viscoplastic strain rate is expressed by

$$
\dot{\varepsilon}_{i j}^{v p}=\Gamma^{v p}\left\langle\Phi\left(\frac{f}{f_{0}}\right)\right\rangle^{N} \frac{\partial g}{\partial \sigma_{i j}},
$$

where \langle\rangle is the Macaulay bracket. In Equation (10), the part within Macaulay bracket can be expressed as [30]

$$
\left\langle\Phi\left(\frac{f}{f_{0}}\right)\right\rangle^{N}=\left\{\begin{array}{ll}
0 & f<0 \\
f & f \geq 0
\end{array} .\right.
$$


According to the extended Drucker-Prager model, the yield function then is obtained as

$$
f=\sqrt{J_{2}}-\lambda I_{1}-\zeta
$$

in which, $\lambda$ and $\zeta$ are the coefficients which can be defined by cohesion $C$ and friction angle $\phi$ with

$$
\left\{\begin{array}{l}
\lambda=\frac{2 \sin \phi}{\sqrt{3}(3-\sin \phi)} \\
\zeta=\frac{6 C \sin \phi}{\sqrt{3}(3-\sin \phi)}
\end{array}\right.
$$

The viscoplastic strain rate described by Wang [19] goes

$$
\frac{\partial \varepsilon_{v p}}{\partial t \gamma_{2}}=d \frac{\sigma-\sigma_{s}}{\eta_{2}}
$$

the yield state of materials yields $\sigma-\sigma_{s}$ in one-dimensional formulation, in three-dimensional stress condition, the yield state of materials is described by $\left\langle\Phi\left(f / f_{0}\right)\right\rangle^{N} \partial g / \partial \sigma_{i j}$ in Equation (10), then for homogenous materials, we have

$$
\Gamma^{v p}=\frac{d}{\eta_{2}}
$$

Submitting Equation (15) into Equation (10), the integration of Equation (10) can be expressed as

$$
\varepsilon_{i j}^{v p}=\frac{D}{\eta_{2}}\left\langle\Phi\left(f / f_{0}\right)\right\rangle^{N} \frac{\partial g}{\partial \sigma_{i j}} .
$$

Referring the damage model of Wang [19] and $\mathrm{Wu}$ [31], the model of total damage in this paper applied the form of

$$
D=\chi t^{\gamma_{2}}+\exp \left[\alpha t^{\gamma_{2}}\right] / \alpha .
$$

As pointed out by Masad [32,33], associative flow rule leads larger volumetric dilation of materials than real results by applying Equation (10). To improve the accuracy computation, You [34] proposed a simple form of viscoplastic potential function as

$$
g=\sqrt{J_{2}}-\beta I_{1} .
$$

Finally, taking Equation (7) to Equations (13), (16) and (17) into Equation (6), we obtain a three-dimensional creep damage-based model as

$$
\varepsilon_{i j}=\left\{\begin{array}{ll}
\frac{1}{2 G_{0}} s_{i j}+\frac{1}{3 K_{0}} \sigma_{m} \delta_{i j}+\frac{s_{i j}}{2 G_{1}}\left[1-\exp \left(\frac{-G_{1} \gamma_{1}}{\eta_{1}}\right)\right] \\
\frac{1}{2 G_{0}} s_{i j}+\frac{1}{3 K_{0}} \sigma_{m} \delta_{i j}+\frac{s_{i j}}{2 G_{1}}\left[1-\exp \left(\frac{-G_{1} \gamma_{1}}{\eta_{1}}\right)\right]+\frac{\exp \left[\alpha t \gamma_{2}\right]-\alpha \chi t^{\gamma_{2}}}{\alpha \eta_{2}} f \frac{\partial g}{\partial \sigma_{i j}} \quad(f \geq 0)
\end{array} .\right.
$$

\subsection{A Permeability Evolution Model}

Analysis on the permeability of granite in above section convinces us that the permeability of granite is related to the volumetric dilation and connectivity of microcracks, although the volumetric compression reduces the permeability as observed by Liu [3], both the measured permeabilities of Liu [3] and this paper suggest neglectable change in the transient and steady state of creep process. Thus, the connectivity of microcracks is the significant factor of permeability evolution. As reveled by Chen [25], see Figure 3d, the connectivity of microcracks will form a meso crack eventually in the accelerated state of creep process, affording a fluid path for seepage. Regarding this meso crack as a tubule, then according to Hagen-Poiseuille's law, the volume flow rate in the porous medium is given by 


$$
Q=\frac{\pi R^{4}}{8 \mu} \nabla P .
$$

In the condition of steady-state flow, the volume flow rate can be also described by Darcy equation as

$$
Q=\frac{k A_{s}}{\mu} \nabla P .
$$

Combining Equations (20) and (21), the permeability of porous medium can be expressed as

$$
k=\frac{\pi R^{4}}{8 A_{s}} .
$$

Please note that, here the permeability $k$ is additional increased permeability due to microcracks connectivity. Thus, the real permeability of porous medium should be

$$
k=k_{0}+\frac{\pi R^{4}}{8 A_{s}} .
$$

The evolution of sectional area of the equivalent tubule can be given by

$$
\pi R^{4}=n\left(3 \varepsilon_{m}-\varepsilon_{i i}\right) A_{s} .
$$

Submitting Equation (24) into Equation (23), in a unit sectional area of the porous medium, the model of permeability evolution in the creep process of granite is then obtained as

$$
k=k_{0}+\frac{n^{2}\left(3 \varepsilon_{m}-\varepsilon_{i i}\right)^{2}}{8 \pi} .
$$

It is notable that, Equation (25) describes the permeability evolution of granite in steady-state flow, due to the application of Darcy equation. Thus, the model validation of this model is according to the measured data of Liu [3], which were measured by steady-state method in creep-seepage experiment.

\section{Model Verification}

To verify the proposed creep model of Equation (19). The creep strain in the last creep step, which contains full regions of a creep process in CS_3 and CS_9 were fitted by the creep model as shown in Figure $6 \mathrm{a}, \mathrm{b}$. The experiment data of creep strain by Liu [3] was also fitted by the creep model as depicted in Figure 6c-e. For the triaxial compressive creep experiment, since $\sigma_{2}=\sigma_{3}$, then we have

$$
\left\{\begin{array}{l}
\sigma_{m}=\frac{\sigma_{1}+2 \sigma_{3}}{3}-p \\
s_{11}=\frac{2\left(\sigma_{1}-\sigma_{3}\right)}{3} \\
\sqrt{J_{2}}=\frac{\sigma_{1}-\sigma_{3}}{\sqrt{3}}
\end{array} .\right.
$$

Equations (19) and (26) were used for fitting the creep strain as in Figure 6. The paremeters used for the calculation are shown in Table 1. Interestingly, although there is difference between the initial volumetric strain of experiment and the proposed model, the model results of creep strain are very close to the experiment of the present paper and Liu [3], especially the strain in accelerated region, in terms of tendency and values. 


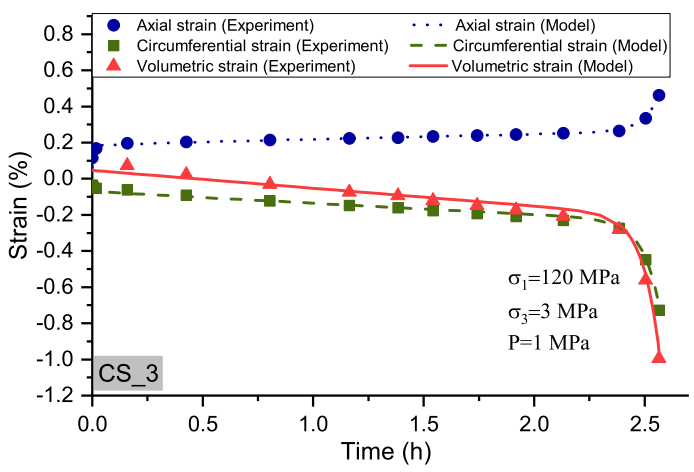

(a)

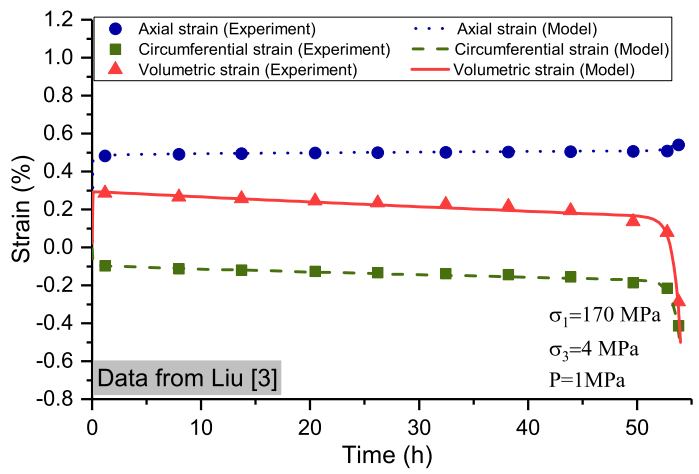

(c)

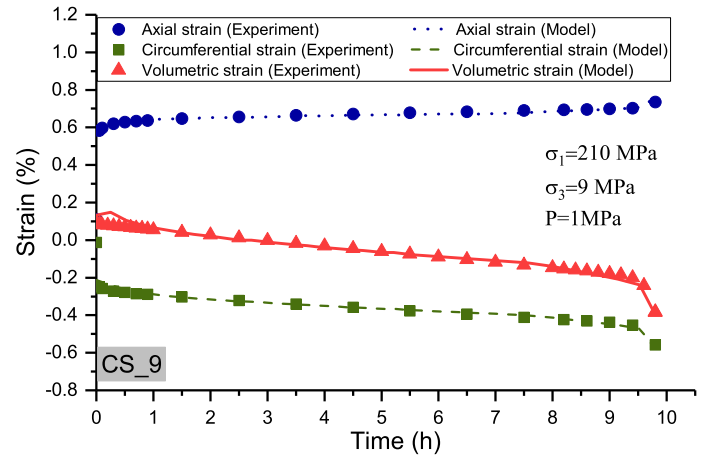

(b)

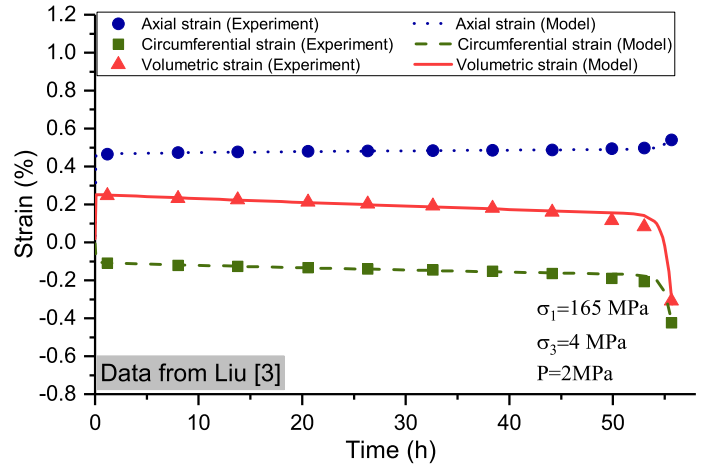

(d)

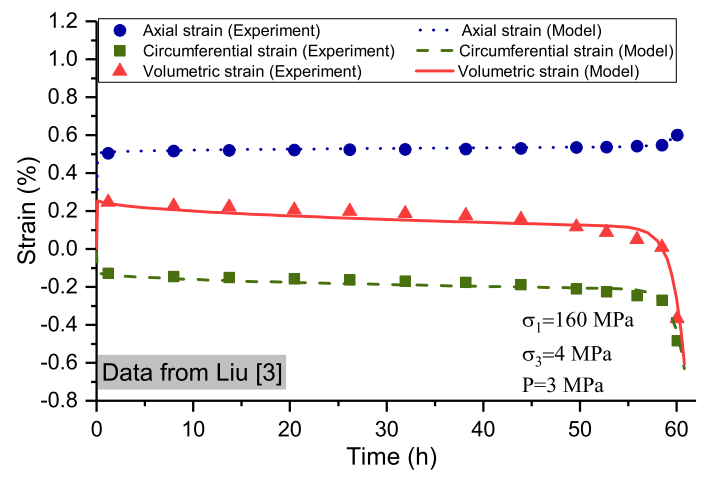

(e)

Figure 6. Experiment data and fitted results of creep strain in the specimen of (a) CS_3 (b) CS_9 and (c-e) that of experiment with hydraulic pressure of $1 \mathrm{MPa}, 2 \mathrm{MPa}$ and $3 \mathrm{MPa}$ by Liu [3].

Table 1. Paremeters for creep strain model.

\begin{tabular}{|c|c|c|c|c|c|c|c|c|c|c|c|c|}
\hline & $\begin{array}{c}E_{0} \\
\text { (MPa) }\end{array}$ & $\begin{array}{c}E_{1} \\
(\mathrm{MPa})\end{array}$ & $\begin{array}{c}v \\
(-)\end{array}$ & $\begin{array}{c}C \\
\text { (MPa) }\end{array}$ & $\begin{array}{c}\phi \\
\left(^{\circ}\right)\end{array}$ & $\begin{array}{l}\gamma_{1} \\
(-)\end{array}$ & $\begin{array}{l}\gamma_{2} \\
(-)\end{array}$ & $\begin{array}{c}\eta_{1} \\
(\mathrm{GPa} \cdot h)\end{array}$ & $\begin{array}{c}\eta_{2} \\
(G P a \cdot h)\end{array}$ & $\begin{array}{l}\alpha \\
(-)\end{array}$ & $\begin{array}{c}\beta \\
(-)\end{array}$ & $\begin{array}{c}\chi \\
(-)\end{array}$ \\
\hline CS_3 & 70000 & 1450 & 0.2 & 28 & 30 & 0.04 & 0.935 & 2.5 & $1.15 \times 10^{16}$ & 16.9 & 0.2 & $4.15 \times 10^{15}$ \\
\hline CS_9 & 70000 & 1450 & 0.24 & 28 & 30 & 0.02 & 0.936 & 1.05 & $1.75 \times 10^{34}$ & 9.63 & 0.29 & $1.3 \times 10^{33}$ \\
\hline Figure $6 c$ & 48000 & 2700 & 0.21 & 28 & 30 & 0.01 & 0.87 & 0.87 & $4.87 \times 10^{40}$ & 2.95 & 0.38 & $3.57 \times 10^{38}$ \\
\hline Figure $6 \mathrm{~d}$ & 48000 & 2700 & 0.24 & 28 & 30 & 0.01 & 0.867 & 0.87 & $1.76 \times 10^{41}$ & 2.94 & 0.32 & $1.16 \times 10^{39}$ \\
\hline Figure 6e & 48000 & 2700 & 0.25 & 28 & 30 & 0.01 & 0.467 & 0.65 & $1.76 \times 10^{44}$ & 15.42 & 0.32 & $8.06 \times 10^{42}$ \\
\hline
\end{tabular}

The measured data of permeability evolution and calculated results by Equation (25) are depicted in Figure 7. Please note that initial permeability and $n$ are involved in the calculation. The permeability measured by steady-state method suggests a slight deduction initially, then a stable state and a dramatic increase in the accelerated creep phase. Since Equation (25) neglected the permeability change induced 
by volumetric compression. The model results in Figure 7 do not have the initial decrease trend. Obviously, the initial change of permeability is very small, the model results match well the experiment data in the steady creep phase and accelerated creep phase.

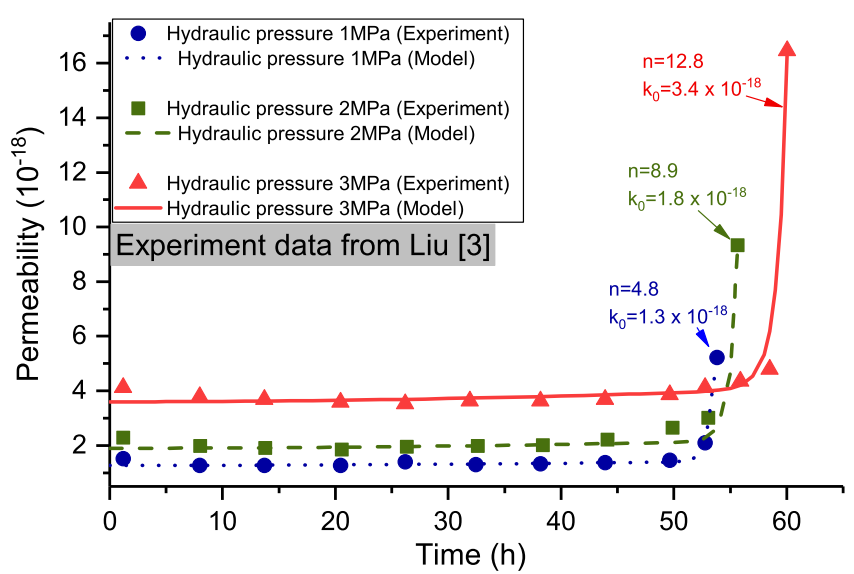

Figure 7. Permeability evolution of model results and experiment data from Liu [3].

Please note that the proposed permeability evolution model is in a simple mathematic formation, in which only one parameter is required for the calculation. As a whole, the calculated results of the three-dimensional damaged-based creep model and permeability evolution model are very close to the experiment data, which verified that both the creep model and permeability evolution model are reliable to reproducing the evolution of creep strain and permeability of granite.

\section{Conclusions}

This paper investigated the permeability evolution of granite in its creep process by triaxial creep-seepage experiments. According to the analysis on the evolution of creep strain and permeability, characters of AE hits, and mechanism of volumetric dilation and permeability evolution. one can draw the conclusions as follows: (1) The permeability of granite is increased significant due to creep damage, especially in the accelerated creep state, which is promoted dramatically, thus the influence of creep damage on the permeability of granite should not be neglected in the engineering design of HLW repositories; (2) Permeability evolution of granite in its creep process is related to the volumetric dilation and the connectivity of microcracks, according to this relationship, a three-dimensional damage-based creep model and a permeability evolution model were deduced in the present paper; (3) The calculated results of the proposed creep model and permeability model match well the experiment data, suggesting the models are reliable to reflect the evolution of creep strain and permeability of granite.

The present paper investigated the relationship between creep strain and permeability evolution, which is significant for design work of the HLW repositories. The developed three-dimensional creep strain model is based on classic visco-elastic-plastic theory, which is easy for numerical implementation. The proposed permeability model is related to volumetric strain, which is simple for calculation due to one parameter required.

Author Contributions: Conceptualization, H.Z.; methodology, H.Y. and R.W.; investigation, D.L. and J.D.; resources, R.W.; data curation, H.Y. and R.W.; writing-original draft preparation, H.Y.; visualization, H.Y.; supervision, H.Z.; project administration, H.Z.; funding acquisition, H.Z..

Funding: This research was supported by National Natural Science Foundation of China (grant number: 51674266) and the State Key Research Development Program of China (grant number: 2016YFC0600704). Appreciation and thanks are given to the organizations for their finical funding herein.

Conflicts of Interest: The authors declare no conflict of interest. 


\section{Notation}

\begin{tabular}{|c|c|c|}
\hline Symbols & Units & Description \\
\hline$K$ & $\mathrm{~m}^{2}$ & Permeability \\
\hline$K_{0}$ & $\mathrm{~m}^{2}$ & Initial permeability \\
\hline$\mu$ & $\mathrm{Pa} \cdot \mathrm{s}$ & Viscosity \\
\hline$\beta$ & $\mathrm{Pa}^{-1}$ & Compressibility \\
\hline$P$ & $\mathrm{~Pa}$ & Hydraulic pressure \\
\hline$V$ & $\mathrm{~m}^{3}$ & Volume of tested specimen \\
\hline$A_{s}$ & $\mathrm{~m}^{2}$ & Cross sectional area of tested specimen \\
\hline$L_{S}$ & $\mathrm{~m}$ & Length of tested specimen \\
\hline$\varepsilon_{m}$ & - & Volumetric strain \\
\hline$\varepsilon_{a}$ & - & Axial strain \\
\hline$\varepsilon_{c}$ & - & Circumferential strain \\
\hline$\varepsilon$ & - & Total strain \\
\hline$\varepsilon^{e}$ & - & Elastic strain \\
\hline$\varepsilon^{v e}$ & - & Viscoelastic strain \\
\hline$\varepsilon^{v p}$ & - & Viscoplastic strain \\
\hline$\sigma$ & $\mathrm{Pa}$ & Stress in Nishihara model \\
\hline$\sigma_{s}$ & $\mathrm{~Pa}$ & Yield strength in Nishihara model \\
\hline$\sigma_{m}$ & $\mathrm{~Pa}$ & Effective volumetric stress \\
\hline$\sigma^{\prime}$ & $\mathrm{Pa}$ & Effective stress \\
\hline$s$ & $\mathrm{~Pa}$ & Deviatoric stress \\
\hline$I_{1}$ & $\mathrm{~Pa}$ & The first invariant of stress tensor \\
\hline$J_{2}$ & $\mathrm{~Pa}$ & The second invariant of deviatoric stress tensor \\
\hline$\delta$ & - & Kronecker symbol \\
\hline$\lambda$ & - & Coefficient of friction angle \\
\hline$\zeta$ & - & Coefficient of cohesion \\
\hline C & $\mathrm{Pa}$ & Cohesion \\
\hline$\phi$ & $\circ$ & Friction angle \\
\hline$E_{0}$ & $\mathrm{~Pa}$ & Elastic mudulus of the elastic part in Nishihara model \\
\hline$E_{1}$ & $\mathrm{~Pa}$ & Elastic mudulus of the viscoelastic part in Nishihara model \\
\hline$G_{0}$ & $\mathrm{~Pa}$ & Shear mudulus of the elastic part in Nishihara model \\
\hline$G_{1}$ & $\mathrm{~Pa}$ & Shear mudulus of the viscoelastic part in Nishihara model \\
\hline$K_{0}$ & $\mathrm{~Pa}$ & Bulk mudulus of the elastic part in Nishihara model \\
\hline$K_{1}$ & $\mathrm{~Pa}$ & Bulk mudulus of the viscoelastic part in Nishihara model \\
\hline$t$ & $\mathrm{~s}$ & Creep time \\
\hline$\alpha$ & - & Damage coefficient \\
\hline$\chi$ & - & Damage coefficient corresponding to linear damage part \\
\hline$\beta$ & - & Constant corresponding to dilation or shrinkage \\
\hline$\gamma_{1}$ & - & Fractal derivative index for the viscoelastic part \\
\hline$\eta_{1}$ & $\mathrm{~Pa} \cdot \mathrm{h}$ & Viscosity of the viscoelastic part \\
\hline$\gamma_{2}$ & - & Fractal derivative index for the viscoplastic part \\
\hline$\eta_{2}$ & $\mathrm{~Pa} \cdot \mathrm{h}$ & Viscosity of the viscoplastic part \\
\hline$\Gamma^{v p}$ & - & Time-dependent coefficient of viscosity \\
\hline$f$ & - & Yield function \\
\hline$f_{0}$ & - & Reference of yield function \\
\hline$g$ & - & Viscoplastic potential function \\
\hline$N$ & - & Sensitivity index \\
\hline$\Phi$ & - & Over-stress function \\
\hline$d$ & - & Damage rate \\
\hline$D$ & - & Total damage \\
\hline$Q$ & $\mathrm{~m}^{3} / \mathrm{s}$ & Volume flow rate \\
\hline$n$ & - & Coefficient related to the connectivity of microcracks \\
\hline
\end{tabular}




\section{References}

1. Wang, J. High-level radioactive waste disposal in China: Update 2010. J. Rock Mech. Geotech. Eng. 2010, 2, $1-11$.

2. Chen, L.; Wang, C.P.; Liu, J.F.; Li, Y.; Liu, J.; Wang, J. Effects of temperature and stress on the time-dependent behavior of Beishan granite. Int. J. Rock Mech. Min. Sci. 2017, 93, 316-323. [CrossRef]

3. Liu, L.; Xu, W.Y.; Wang, H.L.; Wang, W.; Wang, R.B. Permeability evolution of granite gneiss during triaxial creep tests. Rock Mech. Rock Eng. 2016, 49, 3455-3462. [CrossRef]

4. Kranz, R.L.; Blacic, J.D. Permeability changes during time-dependent deformation of silicate rock. Geophys. Res. Lett. 1984, 11, 975-978. [CrossRef]

5. Cao, Y.; Wang, W.; Xu, W.; Wang, R.; Wang, H. Permeability evolution of low-permeability rocks in triaxial creep tests. Chin. J. Rock Mech. Eng. 2015, 34, 3822-3829.

6. Zhang, Y.; Liu, Z.B.; Xu, W.Y.; Shao, J.F. Change in the permeability of clastic rock during multi-loading triaxial compressive creep tests. Géotech. Lett. 2015, 5, 167-172. [CrossRef]

7. Chen, L.; Wang, C.P.; Liu, J.F.; Liu, Y.M.; Liu, J.; Su, R.; Wang, J. A damage-mechanism-based creep model considering temperature effect in granite. Mech. Res. Commun. 2014, 56, 76-82. [CrossRef]

8. Xu, W.Y.; Wang, R.B.; Wang, W.; Zhang, Z.L.; Zhang, J.C.; Wang, W.Y. Creep properties and permeability evolution in triaxial rheological tests of hard rock in dam foundation. J. Cent. S. Univ. 2012, 19, 252-261. [CrossRef]

9. Lockner, D.A.; Byerlee, J.D.; Kuksenko, V.; Ponomarev, A.; Sidorin, A. Observations of quasistatic fault growth from acoustic emissions. Int. Geophys. Ser. 1992, 51, 3-31.

10. Brantut, N.; Heap, M.J.; Meredith, P.G.; Baud, P. Time-dependent cracking and brittle creep in crustal rocks: A review. J. Struct. Geol. 2013, 52, 17-43. [CrossRef]

11. Selroos, J.O.; Follin, S. Overview of hydrogeological site-descriptive modeling conducted for the proposed high-level nuclear waste repository site at Forsmark, Sweden. Hydrogeol. J. 2014, 22, 295-298. [CrossRef]

12. Hashiba, K.; Fukui, K. Time-dependent behaviors of granite: loading-rate dependence, creep, and relaxation. Rock Mech. Rock Eng. 2016, 49, 2569-2580. [CrossRef]

13. Xu, W.; Zhou, J.; Yang, S.; Shi, C. Study on creep damage constitutive relation of greenschist specimen. Chin. J. Rock Mech. Eng. 2006, 25, 3093-3097.

14. Zhu, C.X.; Huai-Ning, R.; Zhu, Z.D.; Luo, R.L. Non-linear rheological damage model of rock. Chin. J. Geotech. Eng. 2008, 30, 1510-1513.

15. Zhu, Y.; Liu, Q.; Kang, Y.; Liu, K. Study of creep damage constitutive relation of granite considering thermal effect. Chin. J. Rock Mech. Eng. 2011, 30, 1882-1888.

16. Zhou, H.W.; Wang, C.P.; Han, B.B.; Duan, Z.Q. A creep constitutive model for salt rock based on fractional derivatives. Int. J. Rock Mech. Min. Sci. 2011, 48, 116-121. [CrossRef]

17. Zhou, H.W.; Wang, C.P.; Mishnaevsky, L.; Duan, Z.Q.; Ding, J. A fractional derivative approach to full creep regions in salt rock. Mech. Time-Dep. Mater. 2013, 17, 413-425. [CrossRef]

18. Wu, F.; Liu, J.F.; Wang, J. An improved Maxwell creep model for rock based on variable-order fractional derivatives. Environ. Earth Sci. 2015, 73, 6965-6971. [CrossRef]

19. Wang, R.; Zhuo, Z.; Zhou, H.W.; Liu, J.F. A fractal derivative constitutive model for three stages in granite creep. Results Phys. 2017, 7, 2632-2638. [CrossRef]

20. Zhou, H.; Liu, D.; Lei, G.; Xue, D.; Zhao, Y. The Creep-Damage Model of Salt Rock Based on Fractional Derivative. Energies 2018, 11, 2349. [CrossRef]

21. Liu, L.; Xu, W.Y.; Wang, H.L.; Wang, R.B.; Wang, W. Experimental studies on hydro-mechanical properties of metamorphic rock under hydraulic pressures. Eur. J. Environ. Civ. Eng. 2016, 20, 45-59. [CrossRef]

22. Jiang, T.; Shao, J.F.; Xu, W.Y.; Zhou, C.B. Experimental investigation and micromechanical analysis of damage and permeability variation in brittle rocks. Int. J. Rock Mech. Min. Sci. 2010, 47, 703-713. [CrossRef]

23. Zhao, L.Y.; Zhu, Q.Z.; Xu, W.Y.; Dai, F.; Shao, J.F. A unified micromechanics-based damage model for instantaneous and time-dependent behaviors of brittle rocks. Int. J. Rock Mech. Min. Sci. 2016, 84, 187-196. [CrossRef]

24. Chen, W.; Konietzky, H. Simulation of heterogeneity, creep, damage and lifetime for loaded brittle rocks. Tectonophysics 2014, 663, 164-175. [CrossRef] 
25. Chen, L.; Liu, J.F.; Wang, C.P.; Liu, J.F.; Wang, J. Creep behavior of the beishan granite under different temperature and stress conditions. Chin. J. Rock Mech. Eng. 2015, 34, 1228-1235.

26. Kato, M.; Nara, Y.; Okazaki, Y.; Kohno, M.; Sato, T.; Sato, T., Takahashi, M. Application of transient pulse method to permeability measurement for clay. J. Soc. Mater. Sci. Jpn. 2018, 67, 318-323. [CrossRef]

27. Jia, C.J.; Xu, W.Y.; Wang, H.L.; Wang, R.B.; Yu, J.; Yan, L. Stress dependent permeability and porosity of low-permeability rock. J. Cent. South Univ. 2017, 24, 2396-2405. [CrossRef]

28. Qi, Y.; Jiang, Q.; Wang, Z.; Zhou, C. 3d creep constitutive equation of modified nishihara model and its parameters identification. Chinese J. Rock Mech. Eng. 2012, 31, 347-355.

29. Perzyna, P. Thermodynamic theory of viscoplasticity. In Advances in Applied Mechanics; Yih, C.S., Ed.; Elsevier: Amsterdam, The Netherlands, 1971; pp. 313-354.

30. Zienkiewicz, O.C.; Cormeau, I.C. Visco-plasticity-Plasticity and creep in elastic solids-A unified numerical solution approach. Int. J. Numer. Method. Eng. 1974, 8, 821-845. [CrossRef]

31. Wu, F.; Chen, J.; Zou, Q. A nonlinear creep damage model for salt rock. Int. J. Damage Mech. 2018. [CrossRef]

32. Masad, E.; Dessouky, S.; Little, D. Development of an elastoviscoplastic microstructural-based continuum model to predict permanent deformation in hot mix asphalt. Int. J. Geomech. 2007, 7, 119-130. [CrossRef]

33. Masad, E.; Tashman, L.; Little, D.; Zbib, H. Viscoplastic modeling of asphalt mixes with the effects of anisotropy, damage and aggregate characteristics. Mech. Mater. 2005, 37, 1242-1256. [CrossRef]

34. You, T.; Al-Rub, R.K.A.; Darabi, M.K.; Masad, E.A.; Little, D.N. Three-dimensional microstructural modeling of asphalt concrete using a unified viscoelastic-viscoplastic-viscodamage model. Constr. Build. Mater. 2012, 28, 531-548. [CrossRef]

(C) 2018 by the authors. Licensee MDPI, Basel, Switzerland. This article is an open access article distributed under the terms and conditions of the Creative Commons Attribution (CC BY) license (http:/ / creativecommons.org/licenses/by/4.0/). 